\title{
Health impact of chronic arsenic exposure in the population of Gyaspur-Majhi village, Patna, Bihar India
}

\author{
S. Abhinav, S. Navin, P. Shankar, M.S. Rahman, R. Kumar, P.K. Niraj, \\ A. Kumar \& A.K. Ghosh \\ Mahavir Cancer Institute and Research Centre, Patna, Bihar, India
}

\begin{abstract}
Arsenic contamination in the groundwater is a serious and widespread global public health problem and India is one of the highly arsenic exposed country with maximum impact in the Ganga-MeghnaBrahmaputra (GMB) plains. A total of 18 districts out of 38 districts of the state of Bihar are highly affected with groundwater arsenic poisoning. Gyaspur-Mahaji village (a flood plain region of river Ganga) of Patna district was under taken for the study on the basis of large number of skin and breast cancer cases along with typical symptoms of arsenicosis diagnosed in Mahavir Cancer Institute and Research Centre, Patna. The study deals with the survey of the entire village with groundwater and blood arsenic estimation with special attention to know the health status of the arsenic exposed population. The study revealed high arsenic concentration in the groundwater in the village. Arsenic in the blood samples indicates biomarker for chronic arsenic exposure. The overall health status of the village people was very poor but the most unfortunate part was the appearance of skin cancer and breast cancer in many of the arsenic exposed population of this village. Although the number of such persons was few, it was still alarming as more persons may be impacted if they continue to drink arsenic contaminated water in future.
\end{abstract}

\section{INTRODUCTION}

Arsenic in the recent times has caused serious health hazards in a huge population inhabiting GangaMeghna- Brahmaputra plains. The entire GangaMeghna Bramhaputra (GMB) plains has high arsenic concentrations $\left(<10 \mu \mathrm{g} \mathrm{L}^{-1}\right)$ in the groundwater. Population residing in these plains are exposed to arsenic which has led to many health-related problems like keratosis, melanosis and different types of cancer (Yunus et al., 2016). In Bihar, presently 18 districts out of 38 districts are affected by arsenic poisoning and it is assumed that a population of about 5 million are consuming arsenic contaminated groundwater with arsenic concentration more than $50 \mu \mathrm{g} \mathrm{L}^{-1}$ (Singh et al., 2014). In the present study, GyaspurMahaji village (a flood plain region of river Ganga) of Patna district was under taken for the study. The study deals with the entire survey of the village along with groundwater and blood arsenic estimation. The health status of the chronic arsenic exposed population was the major objective of the study.

\section{MATERIALS AND METHODS}

\subsection{Location and ethical approval}

The present study was undertaken at Gyaspur-Mahaji village (N25 $\left.30^{\prime} 02.3^{\prime \prime} \mathrm{E} 085^{\circ} 27^{\prime} 14.2^{\prime \prime}\right)$ of Patna, Bihar, India. The population of the Gyaspur- Mahazi village is approximately 3,380 with male population 1,970 and female population 1410 . There are approximately 509 households (Census, 2011) in the village. The research work was approved by the IEC (Institutional Ethics Committee) of the institute as the work was on human subjects. The survey was carried out in February, 2016.

\subsection{Collection and analysis of total arsenic}

Altogether, 58 groundwater samples from hand tubewells (HTWs) were randomly collected in duplicates from each household situated at every $50 \mathrm{~m}$ of distance in the village. The blood samples of the 58 subjects were also collected from the same households. After the collection, all the samples were estimated as per the standardized protocol through Graphite Furnace Atomic Absorption Spectrophotometer (Pinnacle 900T, Perkin Elmer, Singapore) at Mahavir Cancer Institute and Research Centre, Patna, Bihar, India. Data were analyzed with statistical software (Graphpad Prism 5) and values were expressed as Mean \pm SEM.

\subsection{Health assessment}

The suspected people of the four villages included in this study were exclusively interrogated and examined for arsenic related diseases and other health consequences to know their present health status. For this a questionnaire method was prepared, utilized and health related data were extensively collected (Singh et al., 2014). 


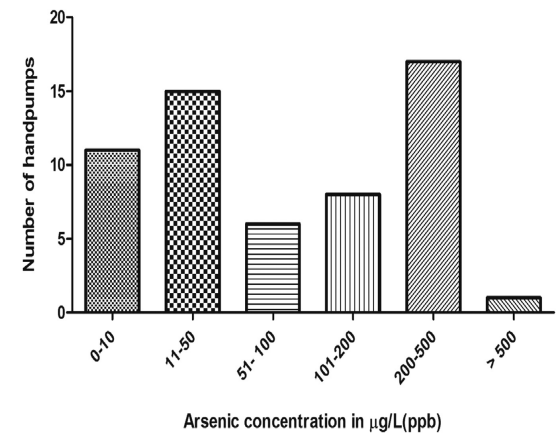

Figure 1. Arsenic concentration in groundwater samples of HTWs of village Gyaspur-Majhi.

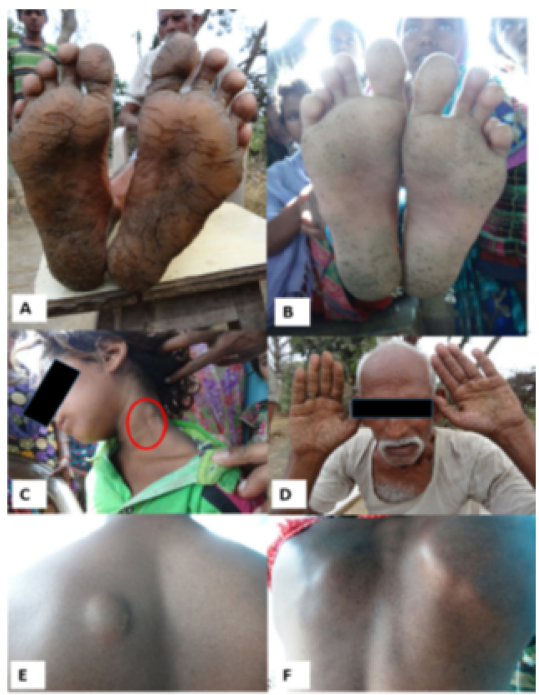

Figure 2. A. Hyperkeratosis of sole in $60 \mathrm{yrs}$ old male (As in drinking water $270.5 \mu \mathrm{g} \mathrm{L}^{-1}$ ); B. Hyperkeratosis of sole in $14 \mathrm{yrs}$ old girl (As in drinking water $368.5 \mu \mathrm{g} \mathrm{L}^{-1}$ ); C. Cervical Nodes in $10 \mathrm{yr}$ old girl (As in drinking water $368.5 \mu \mathrm{g} \mathrm{L}^{-1}$ ); D. Hyperkeratosis of palm in $60 \mathrm{yrs}$ old male (As in drinking water $270.5 \mu \mathrm{g} \mathrm{L}^{-1}$ ); E. Lump at back of $35 \mathrm{yrs}$ old male (As in drinking water $361 \mu \mathrm{g} \mathrm{L}^{-1}$ ); F. Severe melanosis at back of $47 \mathrm{yrs}$ old male (As in drinking water 104.4 $\left.\mu \mathrm{g} \mathrm{L}^{-1}\right)$.

\section{RESULTS AND DISCUSSION}

\subsection{Groundwater and blood arsenic assessment}

The analysis of 58 water samples from the entire village represented high prevalence of arsenic contamination in the groundwater. The maximum arsenic concentration in groundwater sample was $826.4 \mu \mathrm{g} \mathrm{L}^{-1}$. The groundwater samples showed more than $10 \mu \mathrm{g} \mathrm{L}^{-1}$ arsenic concentration in about $89 \%$ of the samples analyzed. Only $11 \%$ samples had normal levels (below $10 \mu \mathrm{g} \mathrm{L}^{-1}$ ), 17\% had levels between $11-50 \mu \mathrm{g} \mathrm{L}^{-1}$ while rest $83 \%$ samples were highly arsenic contaminated water samples (Fig. 1).
The total analyzed 58 blood samples showed arsenic concentration in their blood with $41 \%$ below $1 \mu \mathrm{g} \mathrm{L}^{-1}$ whereas $59 \%$ subjects had the levels more than the permissible limit. The maximum arsenic concentration in blood sample of the village subject reported was $64.98 \mu \mathrm{g} \mathrm{L}^{-1}$ which was extremely very high.

\subsection{Health assessments}

Persons in this village exhibited typical symptoms of arsenicosis like hyperkeratosis in sole and palm, hyperpigmentation in palm (Fig. 2). Many of them exhibited hyperpigmentation (spotted pigmentation) on their whole body, melanosis, cervical nodes on their neck region and tumor at the back (Fig. 2). The most unfortunate part of the study were the cases of cancer, where the first subject (male) reported in our Cancer center with typical symptoms of arsenicosis as hyperkeratosis in sole and palm with rain drop pigmentation over his entire body. The second subject (female) reported with medullary carcinoma of breast. She also exhibited with typical symptoms of arsenicosis as hyperkeratosis on sole and palm.

\section{CONCLUSIONS}

From the study, it can be concluded that the magnitude of arsenic groundwater contamination is severe in the Gyaspur-Majhi village. Prolonged use of arsenic contaminated drinking water leads to various health complications including cancer. Presence of arsenic in the blood samples of the subjects of all the age groups are very alarming. It reflects that there is no any or limited alternate safe source of drinking, cooking and irrigation water supply in these areas. Furthermore, the future health risk can be controlled through supply of safe drinking water.

\section{ACKNOWLEDGEMENTS}

The authors acknowledge support extended by Mahavir Cancer Institute and Research Centre, Patna, Bihar, India for providing laboratory and other infrastructural facilities for this study.

\section{REFERENCES}

Census. 2011. Interim Report of Population Census of India. (http://www.censusindia.gov.in/)

Singh, S.K., Ghosh, A.K., Kumar, A., Kislay, K., Kumar, C., Tiwari, R.R., Parwez, R., Kumar, N. \& Imam, M.D. 2014. Groundwater arsenic contamination and associated health risks in Bihar. India. Int. J. Environ. Res. 8(1): 49-60.

Yunus, F.M., Khan, S., Chowdhury, P., Milton, A.H., Hussain, S. \& Rahman, M. 2016. A review of groundwater arsenic contamination in Bangladesh: the millennium development goal era and beyond. Int. J. Environ. Res. Public Health 13(2): 215. 